UDK: 28-428[641:664.8/.9]

Izvorni naučni rad

Primljeno: 13.3.2019.

Prihvaćeno za štampu: 31.5.2019.

dr.sci. Hakija Kanurić, docent

Univerzitet u Bihaću

Islamski pedagoški fakultet

hakijak@hotmail.com

\title{
ADITIVI I EMULGATORI U HRANI I PIĆU
}

\section{Sažetak}

Hrana i piće ne samo da utječu na tjelesno zdravlje čovjeka nego utječu i na njegovo duhovno stanje, moral i ponaśanje. Postoje opća pravila koja reguliraju pitanja harama $i$ halala $u$ ishrani, a poznavanje istih pomaže nam da razlučimo dozvoljeno od zabranjenog. U procesu proizvodnje hrani se pridodaju raznorazni dodaci s ciljem postizanja boljeg ukusa, mirisa, ljepšeg izgleda, duže trajnosti i sličnih traženih svojstava. Neki od tih dodataka su životinjskog porijekla $i$ često se dobivaju iz dijelova životinja čije meso je zabranjeno ili životinja koje nisu propisno zaklane. Kada se nečiste $i$ zabranjene tvari hemijskom obradom transformiraju $u$ drugu, potpuno razlicitu materiju, da li ta novonastala materija zadržava propis osnove iz koje je potekla ili se pretvorbom u drugu materiju taj propis mijenja? Isto tako, kada se nečista materija u maloj $i$ neznatnoj mjeri pomiješa sa čistom materijom, da li će ta čista materija postati zabranjena ili ne? Islamski pravnici o ovim pitanjima imaju različite stavove, a upravo na tim pitanjima gradi se propis aditiva $i$ emulgatora dobivenih iz zabranjenih sirovina.

Ključne riječi: Islam, hrana, piće, aditivi, emulgatori, halal, haram.

\section{Uvod}

Halal, lijepa i čista hrana ostavit će lijep trag na tijelo i duh čovjeka, a haram i nevaljala hrana suprotno tome. Zbog toga je Svevišnji Allah naredio ljudima da se hrane lijepim jelima, a zabranio im nevaljala, rekavši: "O ljudi, jedite od onoga što ima na Zemlji, ali samo ono što je dopušteno i što je prijatno” (El-Bekara, 168). A opisujući Svog 
poslanika Muhammeda, sallallahu alejhi ve sellem, kazao je: “...koji će im lijepa jela dozvoliti, a ružna im zabraniti.” (El-A'raf, 157)

Čistoća hrane oduvijek je bila briga bogobojaznih. Kur'ansko kazivanje o mladićima iz pećine jasno nam to ilustrira. Ti mladići, kako bi sačuvali svoju vjeru, sklonili su se u pećinu, u kojoj ih je Svevišnji Allah uspavao veoma dug vremenski period, učinivši ih tako znamenjem i poukom. Kada su se probudili i osjetili glad, tragali su za hranom, ali ne bilo kakvom, nego najčišćom, kazali su: "Pošaljite jednog od vas s ovim srebrenjacima vašim u grad, pa nek vidi u koga je najčistije jelo i neka vam od njega donese hrane..." (El-Kehf, 19). Allahov Poslanik, sallallahu alejhi ve sellem, podsticao je vjernike da se hrane dozvoljenim jelima, govoreći: "O ljudi, Allah je lijep i prima samo ono što je lijepo! Naredio je vjernicima ono što je naredio i poslanicima. On kaže: 'O poslanici, dozvoljenim i lijepim jelima se hranite i dobra djela činite, jer Ja dobro znam šta vi radite!' (El-Mu'minun, 51); i kaže: 'O vjernici, jedite ukusna jela koja smo vam podarili.' (El-Bekara, 172). Potom je, veli Ebu Hurejra, radijallahu anhu, prenosilac ovog hadisa, Vjerovjesnik, sallallahu alejhi ve sellem, spomenuo čovjeka raščupana i prašnjava od dugog putovanja koji podigne ruke $\mathrm{k}$ nebu i moli: 'Gospodaru, Gospodaru!', a hrana mu je haram, odjeća mu haram i hrani se haramom, pa kako da takvom bude uslišeno!?"1 Kada haramhrana ne bi imala drugih loših posljedica do odbijanja dove, to bi bio dovoljan razlog da brinemo o čistoći hrane, a kako je tek kada znamo da tijelo koje izrasta iz harama biva preče Džehennemu i dalje od Dženneta i Allahove milosti. Allahov Poslanik, sallallahu alejhi ve sellem, rekao je: "U Džennet neće ući meso i krv koji izrastu na Allahovoj srdžbi, takvom je Vatra preča."2

Nekada ranije, razlučiti haram od halala po pitanju hrane i pića, bilo je mnogo lakše nego što je to slučaj u našem vremenu. Dovoljno je bilo poznavati vrste životinja čije je meso zabranjeno, uvjete klanja, štetne, nečiste i ogavne materije koje je haram konzumirati. Međutim, u našem dobu, kao i na svim drugim poljima života, stvari su se zakomplicirale. Haram se pomiješao sa halalom i naziva se drugim imenima, tako da se mnogi oharame a da toga nisu ni svjesni.

\footnotetext{
${ }^{1}$ Muslim, br. 1015.

${ }^{2}$ Ibnu Hibban, br. 5567. Hadis je sahih po ocjeni Šuajb Arnauta.
} 


\section{Sve stvari u osnovi su dopuštene}

Ovo je generalno fikhsko pravilo koje kaže da je sve u prirodi dozvoljeno sve dok šerijatski argument ne potvrdi suprotno. To znači da je sve ono što je izuzetak iz ovog pravila i tretira se zabranjenim ili pokuđenim pojašnjeno tekstom Zakonodavca u Kur'anu i sunnetu, i da su te zabranjene stvari ograničene i moguće ih je pobrojati. Ovo pravilo implicira da je dozvoljeno sve o čemu šerijat nije dao sud, tako da posebnim ili općim tekstovima nije ukazao na dozvolu niti na zabranu, poput raznih životinja koje se ne spominju u vjerskim izvorima i raznih vrsta bilja.

Na legitimnost ovog pravila ukazuju mnogi dokazi, od kojih su sljedeći kur'anski ajeti:

- "On je za vas sve što postoji na Zemlji stvorio" (El-Bekara, 29). Ovaj ajet navodi se u kontekstu govora o Božijim blagodatima datim čovjeku, te da je Allah za njega sve na Zemlji stvorio, iz čega nužno proizlazi da mu je sve to i dozvoljeno.

- "Reci: 'Ko je zabranio Allahove ukrase, koje je On za robove Svoje stvorio, i ukusna jela?'” (El-A'raf, 32) Ovim ajetom Uzvišeni Allah kori one koji zabrane nešto od onoga što je On stvorio za Svoje robove, što ukazuje na to da je sve u osnovi dozvoljeno, a zabrana je iznimna.

- “On (Allah) vam je objasnio šta vam je zabranio" (El-En'am, 119). Ovim ajetom Allah nam stavlja na znanje da nam je pojasnio zabranjene stvari, tako da sve ono što nije spomenuto nije ni zabranjeno. ${ }^{3}$

Ovo pravilo potvrđuju sljedeći hadisi:

- Poslanik, sallallahu alejhi ve sellem, govorio je: "Doista je najveći grješnik među vama onaj ko upita o nečemu što nije bilo zabranjeno pa se zabrani zbog njegovog pitanja!"” Ovaj hadis jasno ukazuje na to da su sve stvari u osnovi dopuštene. Ako bi neko u vremenu objavljivanja Kur'ana izvještačeno pitao o nečemu što je Allah prešutno dozvolio, propis će biti pojašnjen, a dotična stvar time može postati zabranjena. To znači da je osnova u svemu dozvola, a zabranjeno je samo ono što šerijatski argument zabrani. Ibn Hadžer je rekao: "Ovaj hadis ukazuje

\footnotetext{
${ }^{3}$ Ibn Tejmijja, Medžmul-fetava, 21/536.

${ }^{4}$ Buharija, br. 6745, i Muslim, br. 4349.
} 
na to da je osnova u svim stvarima dozvola, sve dok se šerijatom ne potvrdi suprotno." 5

- Prenosi se od Selmana, radijallahu anhu, da je rekao: "Upitan je Allahov Poslanik, sallallahu alejhi ve sellem, za maslo, sir i krzno, pa je rekao: 'Halal je ono što je Allah dozvolio u Svojoj knjizi, a haram je ono što je Allah zabranio u Svojoj knjizi, a ono što je Allah prešutio, to je oprost i dopuštenje vama." Ovdje Allahov Poslanik, sallallahu alejhi ve sellem, nije dao izravan odgovor na postavljeno pitanje o spomenutim stvarima, nego je ukazao na generalno pravilo za utvrđivanje halala i harama, te da sve ono što Allah nije okarakterisao haramom ostaje dozvoljeno. Ovo je pravilo, također, podržano predajom od Ebu Sa'lebe, radijallahu anhu: “Allah je propisao izvjesne obaveze pa ih nemojte zapostavljati. Definirao je izvjesne granice, pa ih nemojte prelaziti. Postavio je neke zabrane pa ih nemojte kršiti. A neke je stvari prešutio, olakšavajući vama, a ne iz zaborava, zato o tome ne pitajte." 7

Dakle, sve što nalazimo u prirodi u osnovi je halal, a zabranjeno je samo on što je Allah zabranio u Svojoj knjizi ili što je zabranjeno u sunnetu Poslanika, sallallahu alejhi ve sellem.

Također treba istaknuti da učiniti nešto zabranjenim ekskluzivno je pravo Svevišnjeg Allaha. Mnoštvom kur'anskih ajeta Svevišnji je Allah žestoko ukorio predislamske Arape, mnogobošce, koji su po svom nahođenju zabranjivali neke vrste stoke i usjeva. Kaže Uzvišeni: "Reci: 'Kažite vi meni zašto jednu hranu koju vam Allah daje smatrate zabranjenom, a drugu dopuštenom?' Reci: 'Da li vam je prosuđivanje o tome Allah prepustio ili o Allahu laži iznosite?'” (Junus, 59), i rekao je: "I ne govorite neistine jezicima svojim: 'Ovo je dopušteno, a ovo je zabranjeno', da biste tako o Allahu neistine iznosili. Oni koji o Allahu govore neistine - neće uspjeti" (En-Nahl, 116). Štaviše, Svevišnji Allah ubraja govor o Njemu bez znanja među najveće grijehe, zajedno sa

\footnotetext{
${ }^{5}$ Ibnu Hadžer, Fethul-Bari, 13/269.

${ }^{6}$ Tirmizi, br. 1726, Ibnu Madže, br. 3367, Hakim, br. 7115. Hadis je vjerodostojan po ocjeni Hakima, dok je Buharija preferirao da je ovo govor Selmana, radijallahu anhu.

${ }^{7}$ Bejhaki, Es-Sunenul-kubra, br. 19725, Darakutni, Sunen, br. 4396. Bejhaki tvrdi da su ovo riječi ashaba: Ebu Sa'lebe, r.a., a ne riječi Allahovog Poslanika, sallallahu alejhi ve sellem.
} 
širkom. Rekao je: "Reci: 'Ko je zabranio Allahove ukrase, koje je On za robove Svoje stvorio, i ukusna jela?' Reci: 'Ona su za vjernike na ovome svijetu, na onome svijetu su samo za njih.' Eto, tako Mi podrobno izlažemo dokaze ljudima koji znaju. Reci: 'Gospodar moj zabranjuje razvrat, i javni i potajni, i grijehe, i neopravdano nasilje, i da Allahu smatrate ravnim one za koje On nikakav dokaz objavio nije, i da o Allahu govorite ono što ne znate." (El-A'raf, 32-33)

\section{Zabranjena jela i pića}

Nakon što smo potvrdili da je u pravilu svaka hrana dopuštena, a da je zabranjeno samo ono što je Svevišnji Allah zabranio, potrebno je ukazati na opće razloge zabrane određenih vrsta jela i pića, a to su:

Prvo: Opojno dejstvo.

To se odnosi na alkohol i narkotike, koji utječu na razum i izazivaju ovisnost. Svevišnji Allah kaže: "O vjernici, vino i kocka i kumiri i strelice za gatanje su odvratne stvari, šejtanovo djelo; zato se toga klonite da biste postigli što želite" (El-Maida, 90). Allahov Poslanik, sallallahu alejhi ve sellem, govorio je: "Sve što opija haram je. Svevišnji Allah obavezao se da će onog ko pije opojno piće napojiti tekućinom iz habala.' 'A šta je to habal, Allahov Poslaniče?', upita neko. On reče: 'To je znoj i gnoj stanovnika Džehennema.",8

Drugo: Štetnost, koja se reflektira na tjelesno ili umno zdravlje čovjeka. Ovo se odnosi na otrovnu hranu, kao što su neke životinjske i biljne vrste, poput zmija, škorpiona, otrovnih gljiva, a odnosi se i na materije koje nisu otrovne, ali je njihovo konzumiranje štetno, poput zemlje, uglja i sl. Na to ukazuje ajet: "I sami sebe u propast ne dovodite" (ElBekara, 195), kao i ajet: "I sami sebe ne ubijajte!" (En-Nisa, 29). Allahov Poslanik, sallallahu alejhi ve sellem, govorio je: "Šteta se ne smije nanositi niti se štetom uzvraća.",

Treće: Nečistoća.

Ovo se odnosi na nečiste i onečišćene tvari. Primjer nečistih tvari jesu krv koja je istekla prilikom klanja, strvina, svinjetina i sl. Onečišćena

\footnotetext{
${ }^{8}$ Muslim, br. 2002.

${ }^{9}$ Ahmed, br. 2863, Ibnu Madže, br. 2341. Hadis je hasen po ocjeni Šuajba Arnauta.
} 
tvar je u osnovi čista materija kada pod utjecajem nečisti promijeni svoj okus, boju ili miris, kao, naprimjer, kada bi u nekoj hrani uginuo miš ili neka druga životinja. Da se svojstvo čistoće uzima u obzir u ishrani ukazuje ajet: "Reci: "Ja ne vidim u ovome što mi se objavljuje da je ikome zabranjeno jesti ma šta drugo osim strvi, ili krvi koja istječe, ili svinjskog mesa - to je doista pogano (nečisto)...” (El-En'am, 145)

Četvrto: Ogavnost.

To se odnosi na insekte, miševi i sve drugo što je čovjeku zdrave prirode i ukusa odvratno. Opisujući Svog poslanika Muhammeda, sallallahu alejhi ve sellem, Svevišnji Allah kaže: "Koji će im lijepa jela dozvoliti, a ružna im zabraniti” (El-A'raf, 157). ${ }^{10}$

Zabrana ove četiri vrste hrane kompatibilna je sa esencijalnim ciljevima vjere islama. Zaštita ljudskog razuma jedna je od intencija šerijata, jer razum je preduvjet vjerske odgovornosti kao što je preduvjet svakog napretka i uspjeha, stoga je sve što opija islamom zabranjeno. Zaštita života jedan je od ciljeva šerijata, pa je u tom smislu zabranjeno sve što šteti zdravlju čovjeka. Islam udaljava čovjeka od svega što je nečisto ili ogavno, jer od ciljeva islama jeste zaštita ljudske časti i dostojanstva.

Prema tome, zabranjeni su svaka hrana i piće koji utječu na razum svojim opojnim dejstvom, koji su štetni za čovjeka, koji su nečisti ili odvratni ljudima zdrave prirode.

\section{Aditivi i emulgatori}

Hrani se, još od davnina, pridodaju raznorazni dodaci (aditivi) da bi se postigao bolji ukus, ljepši izgled, bolji miris, duža trajnost i sl. Razvojem tehnologije u proizvodnji hrane porastao je i broj aditiva čijim se korištenjem postižu tražena svojstva hrane i ostvaruju bolji rezultati u proizvodnji.

Neke vrste hrane lako oksidiraju čime se gubi kvalitet ili hrana postaje neupotrebljiva za ljude. Nekada se u procesu proizvodnje gubi specifična tražena boja, ili se sastojci hrane međusobno ne spajaju. Ti i slični problemi koji se pojavljuju u proizvodnji hrane suzbijaju se

\footnotetext{
${ }^{10}$ Pogledati: Semerkandi, Tuhfetul-fukaha, 2/63-72, 3/325, Hattab, Mevahibul-Dželil, 3/229, Hejtemi, Tuhfetul-muhtadž, 9/377, Ibnu Kudame, El-Mugni, 9/406.
} 
raznoraznim aditivima. Dodavanjem aditiva hrani postiže se ujednačena kvaliteta proizvoda, ponuda namirnica postaje neovisna o godišnjem dobu, čime se omogućava proizvodnja jeftinije hrane, te njezino dugoročno skladištenje. Aditivi imaju određena pozitivna, ali isto tako i negativna svojstva. Zbog toga su organizacije koje se bave kvalitetom hrane objavile liste dozvoljenih dodataka te u kojim se omjerima smiju koristiti, kako zdravlje potrošača ne bi bilo ugroženo. Međutim, te organizacije u pravilu ne vode računa o tome da li su ti dodaci dozvoljeni sa aspekta šerijata ili ne. Neki od tih dodataka su životinjskog porijekla i često se dobivaju upravo preradom svinjskih ostataka, s obzirom da je to za proizvođače hrane jeftina sirovina. Suvišno je kazati da je upotreba svinjetine u proizvodnji hrane ili njenih dodataka haram, kao i svih drugih nečistih materija, poput strvi i krvi. Međutim, kada se te nečiste i zabranjene tvari ipak upotrijebe nakon što se hemijskom obradom transformiraju u drugu, potpuno različitu materiju, da li ta novonastala materija zadržava propis osnove iz koje je potekla ili se transformacijom u drugu materiju taj propis mijenja? Isto tako, kada se nečiste materije u maloj i neznatnoj mjeri pomiješaju sa čistim materijama, da li će ta čista materija postati zabranjena?

$\mathrm{Na}$ temelju odgovora na ova dva pitanja gradi se propis dodataka hrani dobivenih iz nečistih i zabranjenih tvari, s obzirom na to da se aditivi putem složenih procesa obrade mogu transformirati u potpuno nove materije, a dodaju se u jako malim omjerima tako da se količine koje se koriste za postizanje tehnološkog učinka mjere u miligramima, a samo nekoliko aditiva dodaje se u hranu u gramskim količinama. ${ }^{11}$

\section{Transformacija nečiste materije (istihala)}

Kada islamski pravnici govore o transformaciji kao načinu na koji se nečista materija pretvara $u$ čistu, oni time misle na potpunu transformaciju, $\mathrm{tj}$. preobražaj nečiste materije $u$ potpuno drugu materiju različite hemijske građe, drugih karakteristika, drugog oblika i različitog naziva, tako da nastane jedna sasvim nova materija različita od one prethodne.

\footnotetext{
11 Katalenić, Kemijske i fizikalne opasnosti u hrani: Prehrambeni aditivi, HAH, Osijek, 2010., str. 196.
} 
Treba istaći da islamski pravnici jednoglasno tretiraju transformaciju načinom čišćenja ako se odvija prirodnim putem, bez ljudskog utjecaja, kao kada se alkohol sam po sebi pretvori u ocat, i kao što je pretvaranje krvi gazele u mirisni misk. Međutim, kada se transformacija odvija vještačkim putem, kao što je pretvaranje nečistog ulja i masti u sapun ili da se uginula životinja stavi u sol koja će je razgraditi i pretvoriti u sol, da li je na takav način nastala materija čista ili ne, učenjaci imaju dva oprečna mišljenja.

Prvo mišljenje jeste da se transformacijom ostvaruje čistoća, bez obzira na koji način se desila. To je stav učenjaka hanefijskog i malikijskog mezheba, a odabrao ga je Ibn Tejmijja.

S druge strane, šafijski učenjaci, a to je i odabrani stav hanbelija, tvrde da nečista tvar neće postati čista nakon takve transformacije. ${ }^{12}$

Protagonisti prvog mišljenja pozivaju se na jednoglasan stav učenjaka, da vino postaje čisto kada samo po sebi promijeni svoju prirodu i svoja svojstva i pretvori se u sirće. Analogno tome, kada se i druge nečiste tvari esencijalno transformiraju u potpuno različite tvari, također postaju čiste.

Isto tako, promatrajući prirodu vjerskih propisa, uočavamo da se određena tvar tretira nečistom zbog svojstva pri njoj, pa kada tog svojstva nestane, mijenja se i propis. Tako, naprimjer, grožđe je čisto i halal, ali kada se pretvori u vino, postaje haram, a ako se nakon toga pretvori u sirće, ponovo postaje halal i čisto. To znači da transformacija materije anulira prvobitna svojstva, čime se nužno mijenja i šerijatski propis, jer su nestala svojstva zbog kojih je bila zabranjena.

Protagonisti drugog mišljenja pozivaju se na hadis o zabrani konzumiranja mesa i mlijeka životinje čija je pretežna hrana nečist (džellala). ${ }^{13}$ Ovi učenjaci kažu da, kada bi preobrazba činila nečiste materije čistima, meso i mlijeko takve životinje ne bi bilo zabranjeno. Ovom argumentu oponira to što se učenjaci razilaze u pitanju propisa mlijeka i mesa džellale, jer to neki smatraju zabranjenim, drugi pokuđenim, a treći dozvoljenim. S obzirom na to da u vezi s tim

12 Pogledati: Hašijetu Ibnu 'Abidin, 1/316, Ibnu Kudame, El-Mugni, 1/776, Ibnu Tejmijje, Medžmu'ul-fetava, 21/601.

${ }^{13}$ Ebu Davud, br. 3785 i Tirmizi, br. 1824. Hadis je hasan-garib po ocjeni Tirmizija. 
pitanjem postoji razilaženje, ne može se upotrijebiti kao dokaz po ovom pitanju, jer se prvobitno razilaženje proteže i na ovo pitanje.

Kao argument navode $\mathrm{i}$ to da transformacija često nije potpuna, te da dijelovi nečisti ostaju nepromijenjeni, a time ostaje i svojstvo nečistoće. Međutim, nepotpuna transformacija nije predmet spora, jer i pobornici prvog mišljenja smatraju da ona neće nečistu materiju učiniti čistom. Ovdje se govori o potpunoj transformaciji, koja podrazumijeva cjeloviti preobražaj svih dijelova materije.

Odabrano je prvo mišljenje, da nečist postaje čista kada se potpuno transformira, tako da se ostvari korjenita promjena uslijed koje nastaje potpuno nova esencija, različita od prvobitne u svom hemijskom sastavu, svojstvima i nazivu. Na to ukazuju spomenuti argumenti, kao i činjenica da je propis u kauzalnoj vezi sa svojim uzrokom, te kada je uzrok prisutan, potvrđuje se i propis, a kada je uzrok odsutan, odsutan je i propis. Novonastala materija razlikuje se od nečiste u svojoj suštini, svojstvima pa i nazivu i stoga potpada pod pravilo koje glasi da je svaka tvar u osnovi čista i dozvoljena sve dok se ne potvrdi suprotno. Podržavajući stav da nečist postaje čista kada se transformira, hanefijski učenjak Kuduri kaže: "Kada se zemlja onečisti, a potom trag nečisti nestane pod utjecajem sunca i prolaskom vremena, dozvoljen je namaz na tom mjestu... Razlog za to jeste da zemlja ima svojstvo da tvari pretvara i mijenja u druge vrste, a pretvorba utječe na čišćenje, a na to ukazuje stanje kada se vino pretvori u sirće."14

\section{Iščezavanje nečiste tvari u čistoj (istihlak)}

To je stanje kada se nečista materija u maloj i neznatnoj mjeri pomiješa sa čistom materijom, na način da se u njoj potpuno utroši, istopi i nestane, tako da se njena svojstva i osobenosti potpuno izgube, kao kada bi kap krvi ili alkohola pala u veliku bačvu čiste tekućine, to ne bi ostavilo nikakav trag na ukus, boju ili miris, jer se ta kap utrošila u dominirajućoj tekućini i sasvim nestala. Miješanje nečiste tvari sa čistom na ovakav način, da se ne ostavi trag na ukusu, mirisu ili boji, neće dominantnu čistu materiju učiniti nečistom.

\footnotetext{
${ }^{14}$ Kuduri, Et-Tedžrid, 2/755.
} 
Govoreći o ovom pitanju, Ibn Tejmijja kaže: "Isto tako u pogledu toga kada u tekućinu padne nečist ali je ne promijeni, postoji poznato neslaganje koje je izloženo na drugom mjestu, a očiglednije je da, ako nečist u tome nije ostavila nikakav trag, nego je iščeznula u čistoj tvari, a nije joj promijenila boju, ukus niti miris, čista tvar ostaje čista, a Allah najbolje zna."15

Primijenimo li ova dva pravila na aditive i emulgatore, možemo zaključiti da dodaci hrani, koji su dobiveni iz nečiste i haram materije, ukoliko su kroz proces proizvodnje izgubili prvobitna svojstva, promijenili hemijski sastav i pretvorili se u potpuno nove materije postaju dozvoljeni. Isto tako, ukoliko se nečista tvar u maloj, neznatnoj mjeri pomiješa sa čistom tvari, tako da se ukus, boja i miris nečiste tvari potpuno izgubi, dominantna čista tvar neće time postati zabranjena.

$\mathrm{Na}$ pitanje o prehrambenim artiklima koji u svom sastavu sadrže emulgatore, označene slovom E i brojem nakon njega, Evropsko vijeće za fetve i istraživanje dalo je sljedeći odgovor: "Sastojci koji se označavaju slovom E i brojem nakon njega su dodaci hrani kojih ima preko 350 različitih vrsta. To su konzervansi, bojila, pojačivači ukusa, sladila i sl. Sa aspekta porijekla mogu se svrstati u četiri grupe:

- sastojci dobiveni hemijskim (vještačkim) putem,

- sastojci biljnog porijekla,

- sastojci životinjskog porijekla,

- sastojci rastopljeni u alkoholu.

Propis ovih sastojaka jeste da nemaju utjecaja na dozvolu i zabranu hrane ili pića. To je zbog toga što se prva i druga grupa dobiva iz dozvoljenih tvari, a njihova upotreba ne šteti.

Što se tiče treće grupe, ona se razlikuje od svoje životinjske osnove; jer se hemijskom obradom suštinski transformira i potpuno mijenja tako da se pretvara u potpuno novu i čistu tvar. Ta promjena utječe na šerijatski propis tvari, jer ako je sama materija haram ili nečista, pretvaranjem u novu materiju dobiva novi propis, poput vina kada se pretvori u sirće postaje lijepo i čisto, i tom transformacijom gubi status vina.

${ }^{15}$ Ibnu Tejmijje, Medžmu'ul-fetava, 21/529. 
Što se tiče četvrte grupe, nju pretežno sačinjavaju bojila, a ona se uglavnom koriste u izuzetno malim količinama, tako da (alkohol koji sadrže) bude izgubljen u finalnom proizvodu, a to se prašta i tolerira.

Dakle, hrana i pića koja sadrže nešto od ovih dodataka ostaju halal, i muslimanu ih je dozvoljeno konzumirati. Naša vjera je lahka, zabranjuje nam se izvještačenost i cjepidlačenje, a pretresanje ovakvih stvari nije nam naredio Svevišnji Allah niti Njegov Poslanik, sallallahu alejhi ve sellem."16

Valja podsjetiti da se sve prethodno odnosi na aditive koji se, ako su proizvedeni iz nečiste materije, hemijskom obradom pretvore u potpuno novu materiju, ili se dodaju u tako maloj mjeri da su potpuno izgubi u dominantnoj čistoj materiji ne ostavljajući na njoj bilo kakav trag u ukusu, mirisu i boji. Međutim, proizvodi koji u svojim osnovnim sastojcima sadrže nečistu tvar, kao što je svinjska mast, rum i sl., haram su.

Isto tako, ukoliko se potvrdi štetno djelovanje nekih aditiva po zdravlje čovjeka, iz tog razloga postaju zabranjeni.

Ako je dozvoljenost neke hrane i pića osnovano sumnjiva, propisano je ostaviti je zbog sumnje, međutim nećemo je tretirati haramom sve dok se to jasno ne potvrdi.

\section{Zaključak}

Svevišnji Allah dozvolio je lijepa i čista jela a ružna je zabranio. Lijepa i čista hrana ostavit će lijep trag na tijelo i duh čovjeka, a haram i nevaljala hrana suprotno tome.

Sve u prirodi je dozvoljeno sve dok šerijatski argument ne potvrdi suprotno, a učiniti nešto zabranjenim ekskluzivno je pravo Svevišnjeg Allaha.

Opći razlozi zabrane određenih vrsta jela i pića su: opojno ili narkotično dejstvo, štetnost, nečistoća i ogavnost. Prema tome, zabranjeni su svaka hrana i piće koji utječu na razum svojim opojnim dejstvom, koji su štetni za čovjeka, koji su nečisti ili odvratni ljudima zdrave prirode.

${ }^{16}$ Džizani, Fikhun-nevazil, 4/266. 
Kada se nečist potpuno transformira, tako da se ostvari korjenita promjena uslijed koje nastaje potpuno nova esencija, različita od prvobitne u svom hemijskom sastavu, svojstvima i nazivu, novonastala tvar tretira se čistom, prema odabranom mišljenju islamskih pravnika.

Djelomična, nepotpuna transformacija neće nečistu materiju učiniti čistom.

Ukoliko se nečista tvar u maloj, neznatnoj mjeri pomiješa sa čistom tvari, tako da se ukus, boja i miris nečiste tvari potpuno izgubi, dominantna čista tvar neće time postati zabranjena.

Nečiste i zabranjene tvari nije dozvoljeno upotrebljavati u proizvodnji hrane i piće. Međutim, aditivi i emulgatori dobiveni iz nečiste i haram materije, ukoliko su kroz proces proizvodnje izgubili prvobitna svojstva, promijenili hemijski sastav i pretvorili se $u$ potpuno nove materije nisu zabranjeni.

Ako je dozvoljenost neke hrane i pića osnovano sumnjiva, propisano je ostaviti je zbog sumnje, međutim nećemo je tretirati haramom sve dok se to jasno ne potvrdi.

\section{Literatura:}

1. Ahmed b. Hanbel eš-Šejbani, El-Musned, Muessesetu Kurtuba, Kairo.

2. Bejhaki, Ahmed b. El-Husejn b. 'Ali Ebu Bekr, Sunenul-Bejhaki elKubra, Mektebetud-daril-Baz, Mekka, 1414. h.g.

3. Buhari, Muhammed bin Ismail, Sahihul-Buhari (Buharijeva zbirka hadisa), Daruššsuab, Kairo, 1987. g.

4. Džizani, Muhammed b. Husejn, Fikhun-Nevazil, Daru Ibnil-Dževzi, Ed-Demmam, 1427.h.g.

5. Ebu Davud - Sulejman b. El-Eš'as es-Sidžistani, Sunenu Ebi Davud, Darul-fikr, Bejrut.

6. Hakim, Muhammed b. Abdullah en-Nejsaburi, El-Mustedrak'alassahihajni, Darul-kutubil-'ilmijje, Bejrut, 1411.h.g.

7. Hattab, Šemsud-din Ebu Abdullah Muhammed b. Muhammed, Mevahibul-Dželil lišerhi muhtesari Halil, Daru 'alemil-kutub, ErRijad, 1423. h.g.

8. Hejtemi, Ibnul-Mulekkan, Siradžuddin Ebu Hafs Omer b. Ali, Tuhfetul-muhtadž, Darul-hara', Mekketul-Mukerreme, 1406. h.g. 
9. Ibnu 'Abidin - Muhammed Alaud-din el-Efnedi, Redul-muhtar 'ala edduril-muhtar, Darul-fikr, Bejrut, 1421. h.g.

10. Ibnu Hadžer - Ahmed b. Alij Ebu Fadl el-Askalani, Fethul-Bari šerhus-sahihil-Buhari, Darul-ma'rife, Bejrut, 1379. h.g.

11. Ibnu Hibban - Muhammed b. Hibban b. Ahmed Et-Temimi, Sahihu Ibnu Hibban bi tertibi Ibni Bulban, valorizacija: Šuajb Arnaut, Muessesetur-risale, Bejrut, 1418. h.g.

12. Ibnu Kudame - Abdullah b. Ahmed el-Makdisi, El-Mugni, Darul-fikr, Bejrut, 1405. h.g.

13. Ibnu Madže - Muhammed b. Jezid el-Kazuvejni, Sunenu Ibnu Madže, Mektebetu Ebil-Me'ati, bez godine izdanja.

14. Ibnu Tejmijje - Tekijjuddin Ebu Abbas Ahmed b. Abdulhalim, Medžmu'ul-fetava, Darul-vefa, 1426. h.g.

15. Katalenić Marijan, Kemijske i fizikalne opasnosti u hrani:

Prehrambeni aditivi, HAH, Osijek, 2010.

16. Kuduri, Ahmed b. Muhammed b. Ahmed b. Džafer Ebu Husejn, EtTedžrid, Darus-selam, El-Kahire, 2006.

17. Muslim bin el-Hadždžadž en-Nejsaburi, Sahihu Muslim (Muslimova zbirka hadisa), Daru ihjait-turasil-arabi, Bejrut, bez godine izdanja.

18. Semerkandi, Alauddin, Tuhfetul-fukaha, Darul-kutubil-'ilmijje, Bejrut, 1405. h.g.

19. Tirmizi, Muhammed b. 'Isa Ebu 'Isa, El-Džamius-sahih - sunenutTirmizi, Daru ihjait-turasil-'arabi, Bejrut. 


\section{Hakija Kanurić, PhD}

University of Bihac

Islamic pedagogical faculty

bakijak@botmail.com

Original scientific article

\section{ADDITIVES AND EMULATORS IN FOOD AND BEVERAGES}

\section{ABSTRACT}

Food and drink not only affect the physical health of man, but also affect his spiritual state, morals and behavior. There are general rules that regulate haram and halal issues in nutrition, and knowledge of them helps us to distinguish between allowed and prohibited. Various additives are added in the process of food production in order to achieve better taste, smell, beautiful looks, longer durability and similar required properties. Some of these additives are of animal origin and are often obtained from parts of animals whose meat is forbidden or animals not properly slaughtered. When the unclean and banned substance by chemical treatment is transformed into another completely different matter, does this newly created substance retain the rule of the base from which it has expired or by changing it into another matter that regulation changes? Likewise, when unclean matter is mixed with pure matter in a small and minor measure, will this pure substance become prohibited or not? Islamic lawyers on these issues have different views, and it is precisely on these issues that the rules of additives and emulsifiers derived from prohibited raw materials are being built.

Keywords: Islam, food, drinks, additives, emulsifiers, halal, haram 


$$
\begin{aligned}
& \text { الدكتور المحاضر هاكيا كانوريتش } \\
& \text { جامعة بيهاتش } \\
& \text { كلية التربية الإسلامية } \\
& \text { hakijak@hotmail.com } \\
& \text { المركبات الإضـافية في الأطعمة والأشربة }
\end{aligned}
$$

\section{الخلاصية}

تأثير الطعام والشـراب ليس قاصرا على صحة بدن الإنسان فحسب، بل لهما أثر على

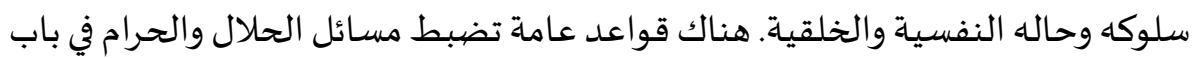
الأطعمة الأشربة ومعرفتها تساعدنا على تمييز ما يحل لنا مما يحرم علينا.

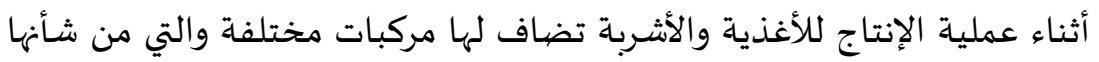
تحسين المذاق والرائحة والمنظر وتطويل مدة الصلاحية ونحو ذلك من المواصفات المرغوبة فيها.

بعض تلك المركبات الإضافية يكون حيوانية المصدر وكثيرا ما تؤخذ من أجزاء

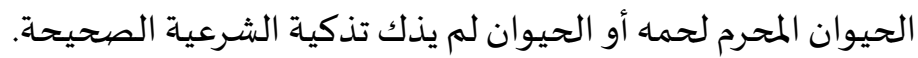

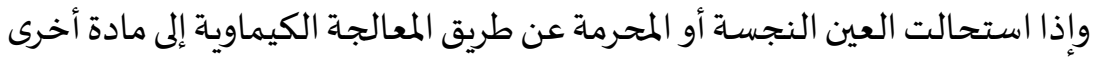

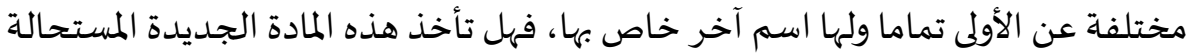

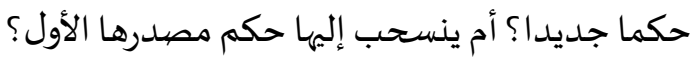
وإذا خالطت العين النجسة في كمية قليلة جدا مادة طاهرة بحيث تستهلك هذه العيل العين

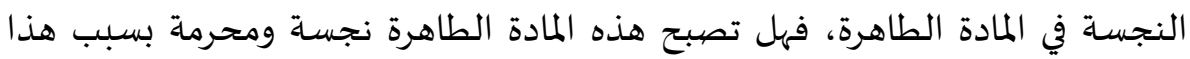
الاختلاط أم لا؟ النجان

وقد اختلف الفقهاء في هذه المسائل واختلفت وجهات أنظارهم وهي المسائل التي

$$
\text { ينبني عليها حكم المركبات الإضافية المأخوذة من المصادر المحرمة. }
$$

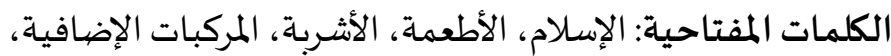

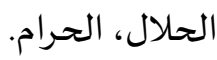

